\title{
Effects of mannoprotein E1 in liquid diet on inflammatory response and TLR5 expression in the gut of rats infected by Salmonella typhimurium
}

\author{
Sinforiano J Posadas', Victor Caz¹, Isabel Caballero', Emilio Cendejas², Immaculada Quilez², Carlota Largo', \\ Marcos Elvira ${ }^{1}$ and Enrique De Miguel*1
}

\begin{abstract}
Background: Mannoproteins are yeast cell wall componend, and rich in mannose. The use of foods rich in mannose as carbohydrate, could have a bioprotective effect against entrobacteria intestinal infection. Nothing is known about mannoproteins' activity in inflammatory bowel processes induced by entrobacteria.

This study investigates the effects of mannoprotein administration via a liquid diet on inflammatory response and TLR5 expression during intestinal tissue injury in a rat model of infection with Salmonella typhimurium.

Methods: Adult Wistar male rats were divided into three groups: control, and mannoprotein $\mathrm{E}_{1}$ at 10 or $15 \%$. Animals were fed with a liquid diet supplemented or not with mannoprotein $E_{1}$. Groups were infected by intragastrical administration of S. typhimurium. $24 \mathrm{~h}$ post-inoculation samples of spleen, ileum and liver were collected for microbiological studies. Gut samples were processed to determine levels of proinflammatory cytokines (mRNA) and TLR5 (mRNA and protein) by quantitative PCR and Western-blot, and the number of proliferative and apoptotic cells determined by immunohistochemistry.
\end{abstract}

Results: Ininfected levels of proinflammatory cytokines and TLR5 were higher in untreated controls than in the animals receiving mannoprotein. Proliferation was similar in both groups, whereas apoptosis was higher in controls. Curiosly, the mannoprotein effect was dose dependent.

Conclusions: Mannoprotein administration in a liquid diet seems to protect intestinal tissue against S. typhimurium infection. This protection seems to expressed as a lower pro-inflammatory response and TLR5 downregulation in gut epithelium, as well as by an inhibition of apoptosis. Nevertheless, the molecular mechanism by which mannoprotein is able to regulate these responses remain unclear. These results could open up new avenues in the use of mannoproteins as prebiotics in the therapeutic strategy for treatment of inflammatory gut processes induced by microbia.

\section{Background}

GRAM-NEGATIVE BACTERIA of the Salmonella enteriditis group are common human pathogens and often isolated from cases of acute food-borne gastroenteritis in developing countries as well as the United States and Europe [1]. S. enteriditis interaction with the intestinal epithelia triggers secretion of chemokines and cytokines and the subsequent luminal translocation of neutrophils

* Correspondence: emiguel.hulp@salud.madrid.org

1 Experimental Surgery Department, La Paz Hospital, Paseo de la Castellana 261, 28046, Madrid, Spain

Full list of author information is available at the end of the article
[2]. The result of this inflammatory response is clinically correlated with acute diarrhea.

Intestinal epithelium is considered an integral and essential component of the innate mucosal immune system [3]. Intestinal epithelial cells (IECs) can respond to enteric pathogens (e.g. Salmonella species, Yersinia enterocolitica, and enteropathogenic Escherichia coli) either by the release of molecules directly endowed with bactericidal properties [4] or by the secretion of proinflammatory mediators [5-8] and the expression of adhesion molecules [9], which permit the recruitment of immune cells and induction of a protective inflammatory 
response that can eradicate pathogens. Many studies have demonstrated that the response by mammalian cells to pathogens is orchestrated through the activation of the nuclear transcription factor $\mathrm{\kappa B}(\mathrm{NF}-\mathrm{\kappa B})[10,11]$ following cell receptor recognition of specific prokaryote motifs called PAMPs (pathogenic associated molecular patterns). Toll-like receptors (TLRs), some of which are expressed by enterocytes, are the best-characterized family of mammalian PAMPs receptors [12]. TLRs recognize an array of prokaryote motifs, including unmethylated CpG DNA motifs, lipopolysaccharides (LPS), lipoproteins, peptidoglycan, and flagellin $[12,14]$, that are shared by both pathogenic and commensal bacteria, suggesting that either type of bacteria may have the potential to initiate innate immune host responses in IECs. Flagellin is a bacterial product that is generally considered a PAMP, with TLR5 as its physiological receptor in vertebrates [15]. In S. typhimurium, bacterial motilility depends on an extracellular filament structure with 20,000 subunits. Purified flagellin can activate transcription and secretion of the proinflammatory chemokine IL-8 in cell culture systems [16]. Flagellin is also a potent activator of systemic inflammation in murine models [17], and, in humans, serum levels of this protein correlate with clinical severity in bacteremic shock syndromes [18], and this indicates a role for this bacterial protein in the immunopathogenesis of inflammatory bowel disease [19]. Interestingly, recent studies indicate that flagellin is able to activate apoptotic signaling pathways. This activation is parallel to a classical proinflammatory pathway and may be a general feature of innate immunity activators of so flagellin may play a previously underappreciated role in host monitoring of, and response to, microbes [20].

Mannoproteins are components of the yeast cell wall; they are $90 \%$ carbohydrate and phosphodiester bonds between lateral manose residue and are widely used for improving the foaming properties in sparkling wines [21]. Mannoproteins are mainly $\mathrm{N}$ - and $\mathrm{O}$ - glycosilate proteins with a highly polymerized and branched glucosilade fraction, with around 150 and 200 mannose residues [22]. It has recentlybeen demonstrated that food supplementation with mannoprotein inhibits gut colonization by Salmonella and other gut bacteria in animals [23-25]. The use of foods rich in manose as carbohydrate in the diet could have a bioprotective effect against intestinal infection caused by entrobacteria [26-28]. Nevertheless, little is known about its iinvolvement in bowel inflammatory processes induced by microbes. Therefore, several clinical studies have been conducted with Saccharomyces boulardii, a yeast species, in the treatment and prevention of various forms of diarrhea, proving it a promising research perspective in the therapy of inflammatory bowel disease [29].
In this manuscript we evaluate the action of a yeast cell wall fraction called "mannoprotein" added to a liquid diet in a rat model of salmonella infection by analyzing the induction of proinflammatory cytokines, and, whether mannoprotein can affect hostexpression of the flagelin receptor TLR5, which is induced by Salmonella.

\section{Methods}

Animals

82 adult Wistar male rats were included in this study and divided in three groups depending on diets: controls $(\mathrm{n}=$ $24)$ and mannoprotein enriched $(\mathrm{n}=58)$ divided by mannoprotein level ( $\mathrm{n}=28$ at $10 \%$ and $\mathrm{n}=30$ at $15 \%)$. Healthy animals came from (Harlan S.A, Spain). and were housed in the Experimental Surgery facilities of La Paz Hospital, in compliance withSpanish law on the protection of experimental animals (RD 1201/2005). All procedures were approved by HULP Animal Care Committee.

\section{Diets}

Animals were caged individually throughout the experiment with free access to. liquid diet (Dietgriff ; $1 \mathrm{Kcal} / \mathrm{ml}$, 16\% Protein, 29\% fat, Lipid and 55\% Glucides) was supplemented either with $10 \%$ and $15 \%$ mannoprotein $\mathrm{E}_{1}$ (BIOMOS Alltech, Inc), mannoprotein a rich product from Saccharomyces cerevisiae, the resulting product was isocaloric, prepared daily and administered during 4 days. Previously different percentages $(2 \%, 5 \%, 10 \%, 15 \%)$ of mannoprotein has been tested to identify the best percentages at which the mannoprotein injected against Salmonella colonization.

\section{Intragastric in vivo inoculation}

Salmonella tiphymurium (ATCC 14028) were grown statically to $3 \times 10^{8} \mathrm{ufc} / \mathrm{ml}$ ( Macfarlan) and sequentially diluted to $10^{3} \mathrm{ufc} / \mathrm{ml}$. This concentration was the minimun needed to produce infection in the animals and to find differences between controls and mannoprotein treated animals using $10 \%$ a $15 \%$ mannoprotein diet. After four days mannoprotein administration rats were anesthetized with isofluorane $(2 \%)$ and innoculated with $1 \mathrm{ml}\left(10^{3} \mathrm{ufc} / \mathrm{ml}\right)$ of the salmonella culture in bicarbonated serum saline $(30 \mathrm{gr} / \mathrm{l})$ by intragastric catheter [3032].

\section{Tissue Sampling}

24 hours after innoculation, animals were killed by sodium phentobarbital i. p. administration $(50 \mathrm{mg} / \mathrm{Kg})$. Spleen, liver and ileum were collected for microbiological studies [30-32]. Samples were homogenized in sodium saline and/placed/in an Agar - Salmonella Shigella and Selenitum enriched medium. Colony identification was made its morphological characteristics and agglutination 
with specific anti-sera to Salmonella poly A and S. typhimurium (Difco).

Samples from the ileum, jejunum and colon were taken and placed in $10 \%$ neutral buffered formalin during $24 \mathrm{hr}$ for Q-PCR and Western-blot assay. Fixed ileum was embedded in paraffin blocks, from which $5-\mu \mathrm{m}$ serial sections were cut for immunohistochemical studies.

\section{Quantification of TLR-5, IL-1 $\beta$, IL- 6 and TNF- $a$ mRNA}

\section{expression. Real time PCR}

Expression levels of TLR-5, IL-1 $\beta$, IL- 6 and TNF- $\alpha$ were detected by real time PCR (LightCycler, Roche Diagnostics, Indianapolis, USA). cDNA from $1 \mu \mathrm{g}$ of total RNA was used for PCR. Real-time PCR was performed with the Fast-Start DNA master SYBR Green system (Roche). The sequences of the primers are as follows:

S26-f: 5' ATGCGTGCCCAAGGACAAGG 3', S26-r: 5'GGCAGCACCCGCAGGTCTAA 3';

IL-1beta-f: 5'AACAGCAATGGTCGGGACAT 3',

IL-1beta-r: 5'GCATTAGGAATAGTGCAGCCATCT 3';

IL-6 -f: 5'TACCCCAACTTCCAATGCTC3'

IL-6-r: 5' TGGACATTCCTCACTGTGGT 3';

TNF- $\alpha$-f: 5 'CACGTCGTAGCAAACC3'

TNF- $\alpha-r$ : 5'GGTGAGGAGCACATAGT3';

TLR-5-f:5' TGTCAACAGGGTGCTTTGTC 3'

TLR-5-r: 5'AAAAGCAGGTGGCTTGAGAA 3'

All results were normalized with respect to the expression of S26. a rhibosomal protein.

The cDNA copy number for each gene of interest was determined using a seven-point standard curve. Standard curves were run with each set of samples. Correlation coefficients (r2) for standard curves were typically $\geq 0.98$. The precision of target S26 from the same cDNA wasquite good, as was the day to day reproducibility. To confirm that each primer pair correctly amplified the sequence of interest, initial PCR products from tissue were run on agarose gel, stained with $0.5 \mu \mathrm{g} / \mathrm{ml}$ ethidium bromide, and viewed by UV transillumination to confirm that a single product of the predicted size was produced. To confirm the specificity of the reaction product during each run, the melting profile of each sample was analyzed using the LightCycler. The melting profile was determined by holding the reaction at $80^{\circ} \mathrm{C}$ for $10 \mathrm{~s}$ and then slowly heating to $95^{\circ} \mathrm{C}$ with a linear rate of $0.1^{\circ} \mathrm{C} / \mathrm{s}$ while measuring the emitted fluorescence. Melting curve analysis demonstrated that each of the primer pairs described amplified a single product. The rare samples that demonstrated a significant second peak in the melting profile were not used in analysis.

\section{TLR-5 Western-Blot}

To demonstrate potential changes in TLR5 expression, western blotting was performed on total protein samples isolated from jejune, ileon and colon tissues using RNADNA-protein separation reagent (Progen Industries, Brisbane, Australia). First, the protein concentration was quantified using Bradford reagent (Sigma, St. Louis MO) with BSA as a standard. Equal amounts of protein $(10 \mu \mathrm{g})$ from each sample, and $2 \mu \mathrm{g}$ of biotinylated broad range protein molecular weight markers (Bio-Rad, Hercules, CA) were treated with a reducing sample buffer; samples were then separated on a $12.5 \%$ SDS-PAGE minigel, and electroblotted onto $0.2-\mu \mathrm{m}$ nitrocellulose membranes (Amersham) $\left(100 \mathrm{~V}, 500 \mathrm{~mA}, 4^{\circ} \mathrm{C}, 40 \mathrm{~min}\right)$. Membranes were blocked for $2 \mathrm{~h}$ in $5 \%$ bovine serum albumin (BSA) and then incubated overnight with a rabbit TLR5 polyclonal IgG antibody (Santa Cruz Inc., USA) at a concentration of 1:750. After primary antibody incubation, membranes were washed $5 \times 10 \mathrm{~min}$ in tris (hydroxymethyl) aminomethane-buffered saline (TBS), with the third 10-min washing in TBS with $0.05 \%$ Tween-20, and then incubated for $1 \mathrm{~h}$ at $4^{\circ} \mathrm{C}$ with a 1:10.000 dilution of peroxidase-conjugated swine anti-rabbit biotinylated IgG and avidin/biotinylated horseradish peroxidase reagents (Dako). Membranes were then washed for $5 \times 10 \mathrm{~min}$ in TBS, followed by a 60-s wash in enhanced chemiluminescence reagents (Amersham). High-performance luminescence detection film (ECL-PLUS, Amersham, Sweeden) was exposed to membranes in a film cassette for between $10 \mathrm{~s}$ and $2 \mathrm{~min}$ and developed. Western-blot of $\beta$-tubuline was used as an internal control.

\section{Apoptosis and proliferation assay: Immunostaining}

To analyze any potential site-specific changes in the member of either apoptotic or proliferative positive cells in the Ileum samples in the two groups examined, immunohistochemical detection of Ki-67 antigen or TUNEL were performed on paraffin sections of the ileum. The ki67 was detected as follows: After removal of paraffin with xylene, by endogenous peroxidase blocking in all tissues with $3 \% \mathrm{H} 2 \mathrm{O} 2$ in methanol. All tissue sections were pretreated in a microwave oven in citrate buffer at $\mathrm{pH} 6.0$ for 10 minutes at $300 \mathrm{~W}$. Unspecific binding sites were blocked using washing buffer 1 (no. K5006; DAKO, Glostrup, Denmark) before incubation with the primary antibody. Slides were incubated for 1 hour at room temperature with the primary antibodies. As primary antibodies, we used monoclonal antibody MIB- 5 (antibody concentration $0.2 \mathrm{mg} / \mathrm{ml}$, no. 2093; Immunotech, Marseille, France. To avoid background due to secondary antibody binding to mouse immunoglobulins in the tissue, MIB-5 was biotinylated using the Animal Research Kit Peroxidase (no. K3954; DAKO) according to the manufacturer's instructions before immunostaining. As a detection system, a streptavidin-peroxidase complex included in the kit was used with a 3.3'-diaminobecidine (DAB) substrate (Sigma). A normal rabbit serum was used as a negative control. For TUNEL: Five- $\mu \mathrm{m}$ sections of formalin-fixed, paraffin-embedded renal tissue were dewaxed, rehydrated, washed in PBS, and incubated in 
terminal deoxynucleotidyl transferase (TdT) buffer for 10 $\mathrm{min}$ at room temperature before incubation with $\mathrm{TdT}$ enzyme (Promega, Madison, WI) and digoxigeninlabeled dUTP (Boehringer Mannheim, Mannheim, Germany) for $1 \mathrm{~h}$ at $37^{\circ} \mathrm{C}$. After the sections were washed in PBS, a sheep anti-digoxigenin $F(a b)_{2}$ was applied for $1 \mathrm{~h}$ at room temperature. Endogenous peroxidase was blocked, and a peroxidase-conjugated rabbit anti-sheep antibody was applied followed by a peroxidase-conjugated swine anti-rabbit antibody. The reaction was developed with the use of a Pierce metal-enhanced diaminobenzidine substrate (Rockford, IL). On the basis of terminal deoxynucleotidyl transferase mediated dUTP nick end labeling (TUNEL) staining and morphologic changes, the apoptotic cells were counted under light microscope in 50 glomerular cross sections and 10 random areas of 0.15 $\mathrm{mm}^{2}$ in the interstitium, with the use of a grid at $400 \mathrm{x}$ magnification. Negative controls without TdT enzyme and positive controls with DNase treatment were included for each tissue. No paraffin-embedded tissues of the PAN model were available to assess apoptosis by TUNEL technique at week 17.

\section{Statistical analysis}

Results of degree of infection, Q-PCR (cytokine and TLR5 gene expression), Western-blot (TLR5 protein levels) and immunohistochemistry (number of ki-67 antigen and apoptotic positive cells) in the different groups were compared with one-way ANOVA.

\section{Results}

\section{Results of microbiological study}

24 hours after Salmonella inoculation $\left(10^{3} \mathrm{ucf} / \mathrm{ml}\right), 9 / 24$ $(37.5 \%)$ of the animals in the control group were infected in at least one of the tissues analyzed in the microbiological analysis. Nevertheless, in the animals treated with $10 \%$ mannoprotein $E_{1}$ the infection rate was lower 8/28 (28.6\%), moreover the animals treated with $15 \%$ mannoprotein $E_{1}$ showed an even lower infection rate --3/30 (10\%)-- and only one tissue type was infected in 11 of the 58 mannoprotein-treated animals. Interestingly, the Salmonella dosis was optimized to $10^{3} \mathrm{ucf} / \mathrm{ml}$, the level at which there were differences between groups treated with mannoprotein. The first comparison of infection levels between two groups (controls and 10\% mannoprotein $\mathrm{E}_{1}$ ) was statistically non significant with a $\mathrm{p}<0.54$ and a difference of $8.9 \%$, meaning that although mannoprotein had reduced infection, the decrease was not significant. Comparing controls with rats receiving 15\% mannoprotein $E_{1}$ showed significant differences in infection rate $(\mathrm{p}<0.05)$, as the percedntage of infected animals (intestinal colonization) was reduced by $27.5 \%$, thus indicating a dose dependency (difference control vs $10 \%$ vs $15 \%)$. Interestingly, infection was found in one or more tissues in the control group animals, whereas in the mannoprotein groups, no animal had infection in more than one tissues type, and in all cases the infection was limited to the ileum homogenates, which necessarily included material from the lumen. Notably, when we evaluated bacterial translocation (regional and/or systemic levels), mannoprotein resulted in a significant decrease from intestinal lumen (local level) to liver and spleen since $44 \%$ of controls showed translocation, and $0 \%$ of either of the $10 \%$ and $15 \%$. mannoprotein treated groups showed infection beyond the local level.

Table 1 shows the results in percentages of the degree of infection and number of tissues affected in all study groups.

Tissue was taken from the Salmonella infected rats for molecular biology and immunohistochemistry study (control, $\mathrm{n}=9$; mannoprotein 10\% E1, $\mathrm{n}=8$ ). The number of infected rats $(n=3,10 \%)$ in the Manoprotein 15\% E1 group was too low to allow statistically significant analysis and so were not included in the following studies.

\section{Analysis of mRNA expression of IL-6, TNF-alpha, IL-1 beta and TLR5 in ileal, colon and jejunum samples}

Proinflammatory cytokines and TLR5 were determined by quantitative RT-PCR analysis, which measured the changes in gene transcription. Changes were significant at the mRNA level in intestinal ileum, colon and jejunum mucosa.,.

\section{mRNA expression in jejunum}

Figures $1 \mathrm{~A}, \mathrm{~B}, \mathrm{C}$ and $1 \mathrm{D}$ illustrate the results for IL-6, TNF-alpha, IL-1beta and TLR5 levels respectively as a ratio of mRNA expression compared with the expression

Table 1: Results of microbiological study

\begin{tabular}{|c|c|c|c|c|}
\hline Group & $\mathbf{N}$ & $\%$ infected Rats & $\begin{array}{c}\% \text { of infected rats with } \geq 2 \\
\text { organs affected }\end{array}$ & $\begin{array}{c}\% \text { of infected rats with } 1 \text { organ } \\
\text { affected }\end{array}$ \\
\hline Control & 24 & $37.5(\mathrm{~N}=9)$ & $44.4 \%$ of $37.5 \%(N=4)$ & $55.6 \%$ of $37.5 \%(\mathrm{~N}=5)$ \\
\hline Mannoprotein 10\% E1 & 28 & $28.6(\mathrm{~N}=8)$ & $0 \%$ & $100 \%(\mathrm{~N}=8)$ \\
\hline Mannoprotein 15\% E1 & 30 & $10 \%(\mathrm{~N}=3)$ & $0 \%$ & $100 \%(N=3)$ \\
\hline
\end{tabular}


A

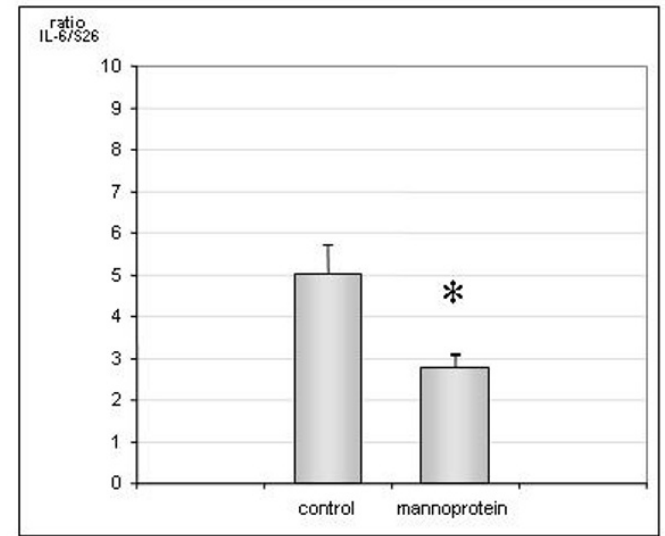

C

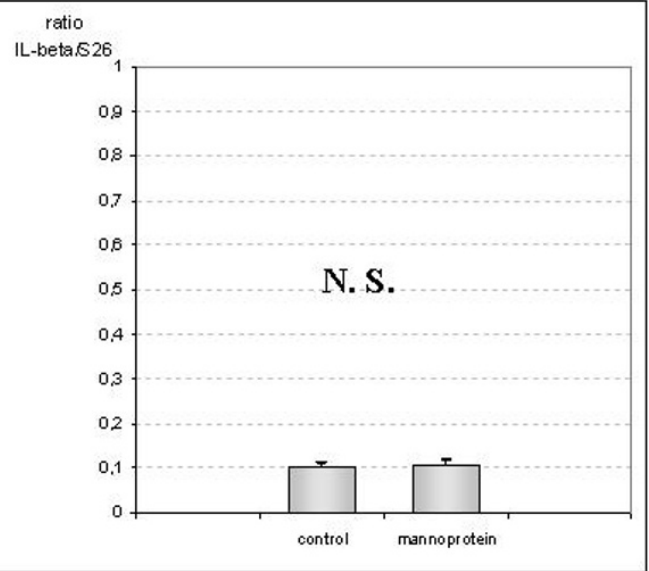

$\mathbf{B}$

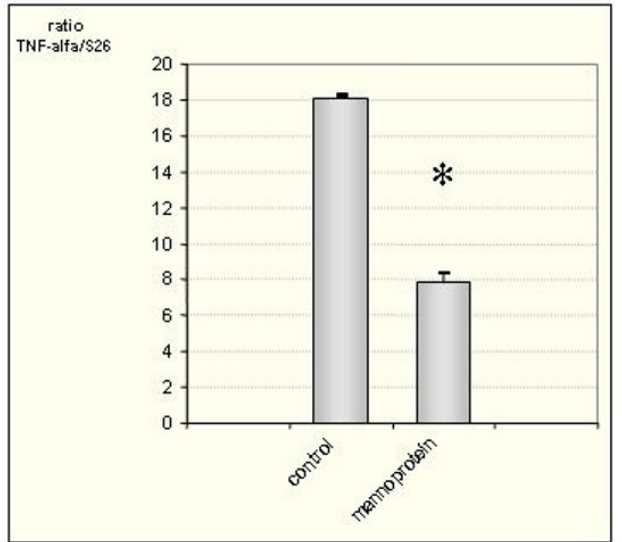

$\mathbf{D}$

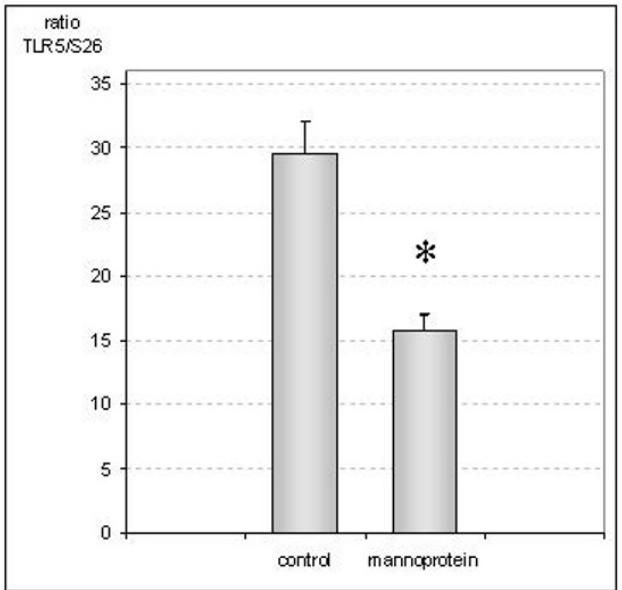

Figure 1 Quantification of IL-6, TNF- $\boldsymbol{a}$, IL-1 $\beta$ and TLR5 mRNA in jejune samples. Figure $1 \mathrm{~A}$ and $1 \mathrm{~B}$ illustrate in a bar diagrams that IL-6 and TNFa mRNA expression increased markedly in control group compared with mannoprotein. Figure 1C shows IL-1 $\beta$ mRNA expression in both groups represented as bars diagram ( $n=9$ control group, $n=8$ mannoprotein group). No statistical differences were observed between both groups. Finally, figure 1D shows the results for TLR5 gene expression in both groups with augmented levels in the control group compared with mannoprotein. Error bars represent the standard deviations. ${ }^{*}$ Significant at $p>0.05$ compared with control.

of the S26 gene, which was employed as a housekeeping gene. IL-6 levels were higher in the control group than in the mannoprotein-treated animals $(\mathrm{p}=0.001$; figure $1 \mathrm{~A})$. Levels of TNF-alpha and IL-1beta were also higher in the control group than the mannoprotein treated animal group ( $\mathrm{p}=0.001)$ in both analyses. Levels of TLR5 mRNA expression also differed significantly between groups ( $\mathrm{p}<$ 0.001 , figure 1D).

\section{mRNA expression in Ileum}

As in the jejunum, IL-6, TNF-alpha and IL-1beta levels were also higher in the control group than in the mannoprotein treated group $(\mathrm{P}<0.001)$ (figures $2 \mathrm{~A}, \mathrm{~B}$ and $2 \mathrm{C}$ ). However, TLR 5 mRNA expression levels showed no differences between the two groups (figure 2D).

mRNA expression in Colon

Proinflammatory cytokine mRNA expression and TLR5 levels were similar in colon to levels in jejunum with the controls showing higher IL-6 levels than the mannoppro- tein-treated animals $(\mathrm{P}<0.001$; figure $3 \mathrm{~A})$. TNF-alpha and IL-1beta levels were higher in the control group than the mannoprotein-treated group $(\mathrm{P}<0.001)$ in both analyses (figure $3 \mathrm{~B}$ and $3 \mathrm{C}$ ). TLR5 gene transcription levels also showed statistical differences between the two groups. $\mathrm{P}<0.001$; figure $3 \mathrm{D}$.

\section{Protein levels of TLR5 in jejunum, Ileum and Colon}

The results of TLR5 protein expression showed higher levels in the control group than the mannoproteintreated group in the three tissues studied (figure 4). TLR5 levels were similar in jejunum, Ileum and colon in the controls. The greatest significant differences between groups were found in the Ileum ( $<<0.009$, figure 4B). However, the differences in TLR5 expression levels in jejunum and colon seem to be similar in all groups ( $\mathrm{p}<$ 0.05 , figure $4 \mathrm{~A}$ and $4 \mathrm{C}$ ). Figure $4 \mathrm{D}$ illustrates a representative picture of TLR5 and beta-tubuline Western-Blot result for both groups in jejunum and Ileum. 
A
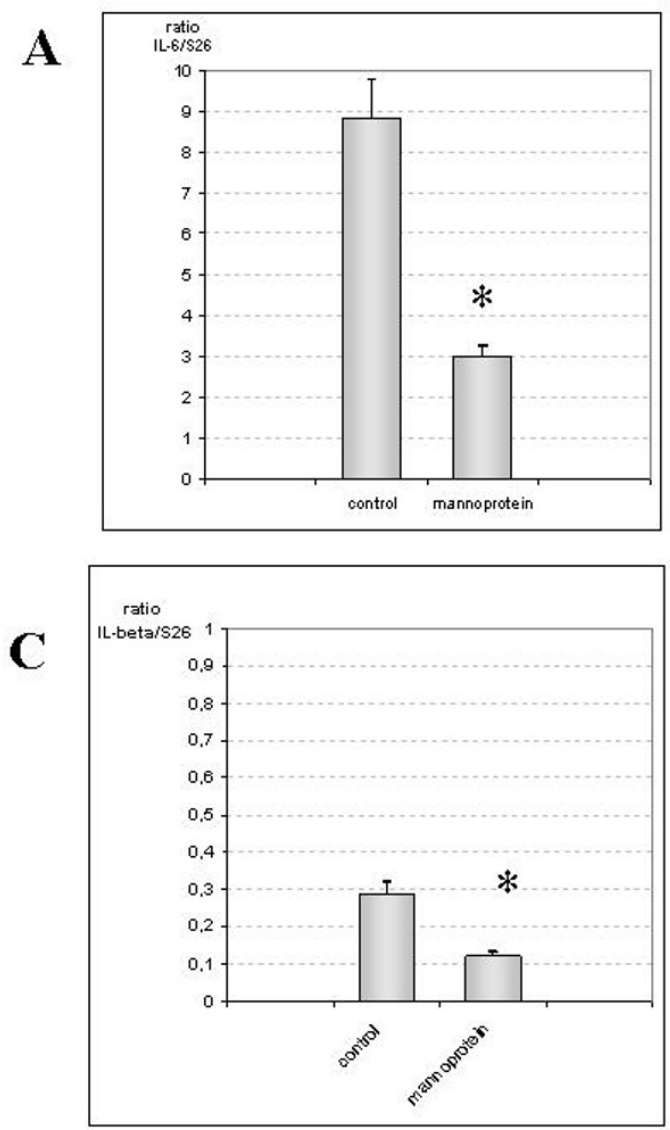

B

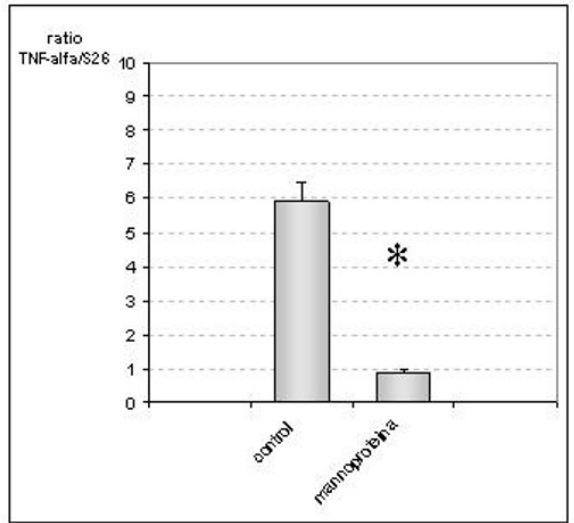

D

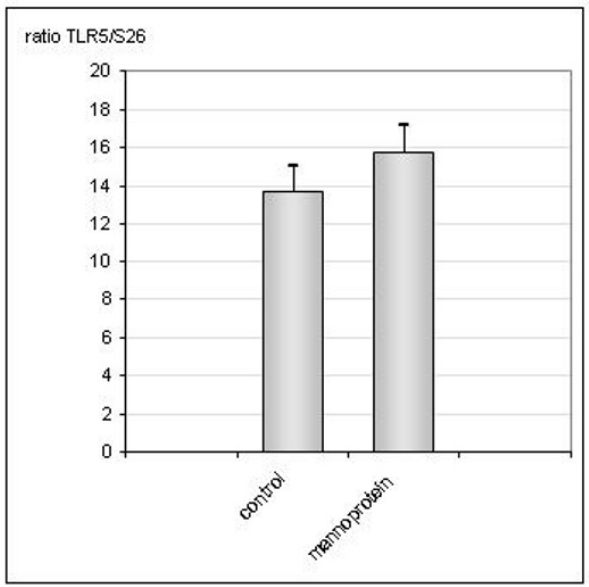

Figure 2 Quantification of IL-6, TNF- $\boldsymbol{a}$, IL-1 $\beta$ and TLR5 mRNA in Ileum samples. Figure 2A and 2B illustrate in a bar diagram that IL-6 and TNF- $\alpha$ mRNA expression increased markedly in control group compared with mannoprotein( $n=9$ control group, $n=8$ mannoprotein group). Figure $2 \mathrm{C}$ shows IL-1 $\beta$ mRNA expression in both groups represented as a bar diagram, with higher and significant levels in the controls. Finally, figure $2 \mathrm{D}$ shows the results for TLR5 gene expression in both groups with no differences in the control group compared with mannoprotein. Error bars represent the standard deviations. * Significant at $p<0.05$ compared with control.

\section{Immunohistochemical findings}

\section{Results on proliferation and apoptosis}

Apical Ki-67 antigen immunohistochemistry in the intestinal Ileum and colon crypts and villi

The data showed insignificant differences in the number of Ki-67 positive cells in the different study groups. Positive cell staining for proliferation was found mainly in the central villi and crypts. The bar diagram in figure $5 \mathrm{~A}$ illustrates the results in number of positive cells per villi for both the control and the mannoprotein treated groups. Figure 5B shows a representative picture of tissue and positive staining (arrows) for each group.

Regarding apoptosis immunoreactivity, our data showed significant differences between the two groups ( $p$ $<0.001$ ). Interestingly, apical immunoreactiviy showed an increase in the control group compared to the mannoprotein treated group - see figure $6 \mathrm{~A}$. These results are expressed in a bar diagram indicating number of positive cells per villus. Figure 6B shows a representative picture of tissue and positive staining (arrows) for each group.

\section{Discussion}

Recent molecular-based investigations have confirmed the species diversity and metabolic complexity of human microbiota. It is also increasingly clear that human gut microbiota have a crucial impact on host health, both as a source of infection and environmental insult and, conversely, as protection against disease by maintaining gut function. Thus, investigators are beginning to develop microbiota management employing by probiotics and prebiotics, including mannoprotein [33]. Nevertheless, little information is available in the literature to analyze the effects in the gut of the molecular components of proprebiotics during a bacterial infection. This manuscript evaluates the effects of mannoprotein, a component of the yeast cell wall, in a rat model of Salmonella infection. 

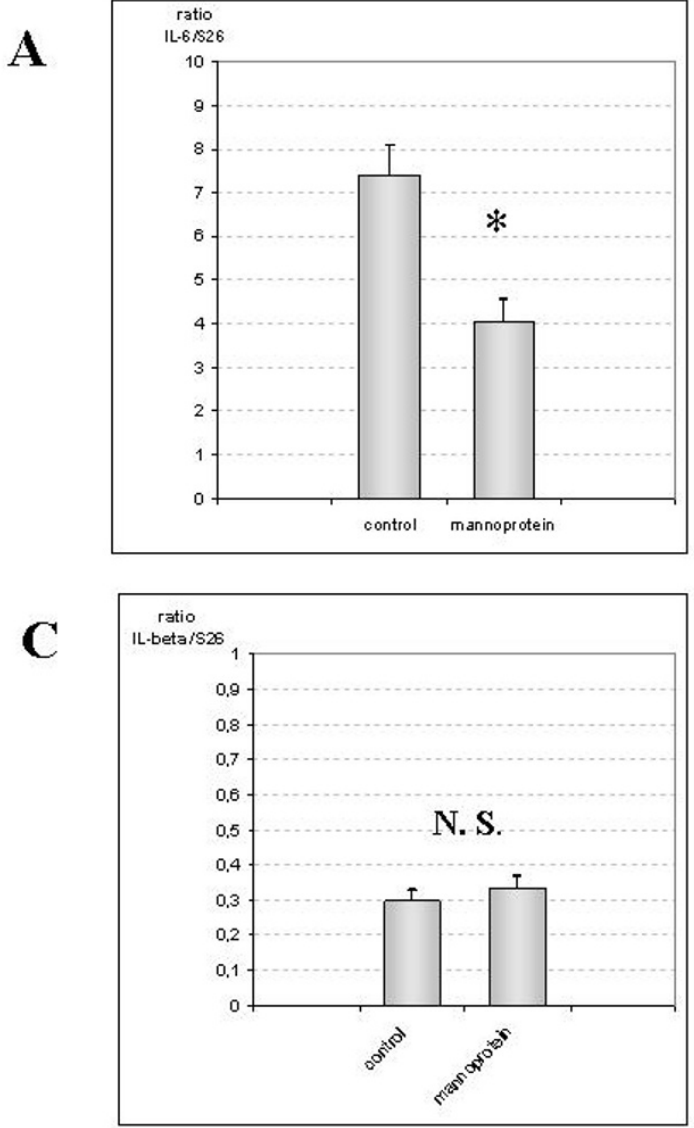

B

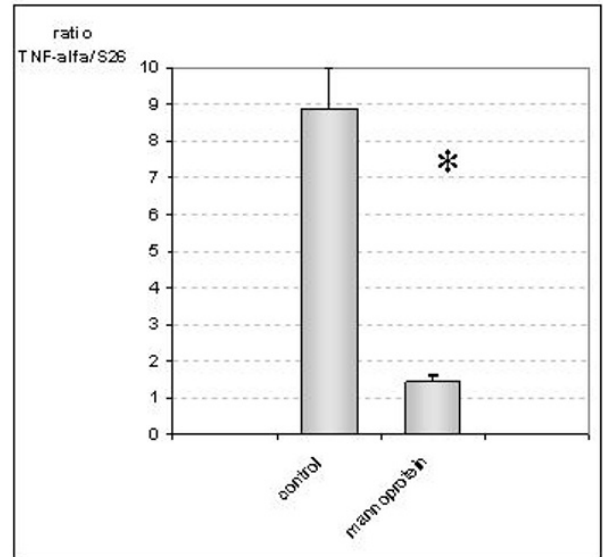

D

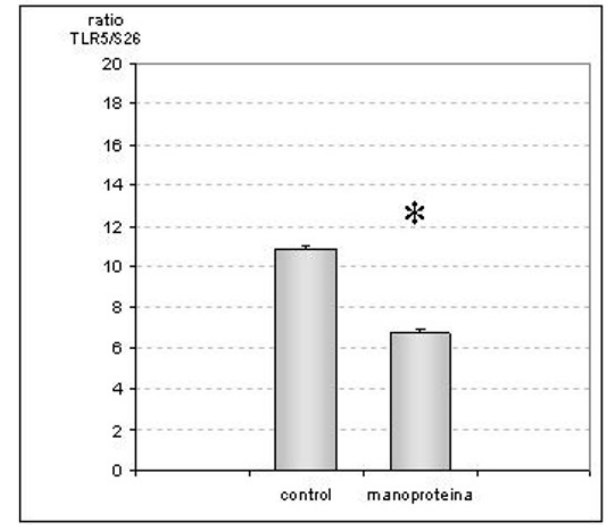

Figure 3 Quantification of IL-6, TNF- $\boldsymbol{a}$, IL-1 $\beta$ and TLR5 mRNA in colon samples. Figure 3A and 3B illustrate in a bar diagram that IL-6 and TNF- $\alpha$ mRNA expression increased markedly in control group compared with mannoprotein ( $n=9$ control group, $n=8$ mannoprotein group). Figure $3 C$ shows IL-1 $\beta$ mRNA expression in both groups represented as a bar diagram. No statistical differences were observed between both groups. Finally figure 3D shows the results for TLR5 gene expression in both groups with augmented levels in the control group compared with mannoprotein. Error bars represent the standard deviations. * Significant at $p<0.05$ compared with control.

Microbiological analysis revealed a protective effect by these compounds that decreased the number of animals infected and the number of organs (spleen, liver and gut) invaded by the infection. Furthermore, at a molecular level, the infected animals treated with mannoprotein showed a lower pro-inflammatory response than the untreated infected control animals, which did not receive mannoprotein.

It is generally assumed that an intestinal proinflammatory mechanism is a characteristic response to pathogenic intestinal bacteria, whereas the commensal bacteria should not induce this response, which interrupt the symbiosis between the bacteria and their mammalian host. Epithelial cells lining the gut have recently been identified as key players in the regulation of the initial steps of host proinflammatory responses to intraluminal bacteria via their controlled expression of PAMP receptors. One attractive hypothesis is that intestinal epithelial cells are hyporesponsive to commensal intraluminal bacteria because of the low PAMP receptor number on the apical surface on the epithelial cells [22], whereas invasive bacteria have access to, and can activate, PAMP receptors in the intracellular space or on the basolateral membrane. In support of the hypothesis, our study shows that mannoproteins apparently modulate the proinflammatory response either because they form a physical barrier to the Salmonella infection or they disrupt the interaction required for activation of $\mathrm{NF}-\mathrm{kB}$ at a given molecular level, thus blocking further signalling cascades beyond that level. Induction of the NF-kB pathway relies on the interaction of flagellin, which is common to all flagellated bacteria, with the TLR5 expressed in situ in the ileum, in both the basal and apical compartments of the epithelial cells and enterocytes. In fact, mannoproteins inhibited campylobacter adherence and invasion of Caco- 2 cells in a recent in vitro study [34]. Thus, mannoproteins would 

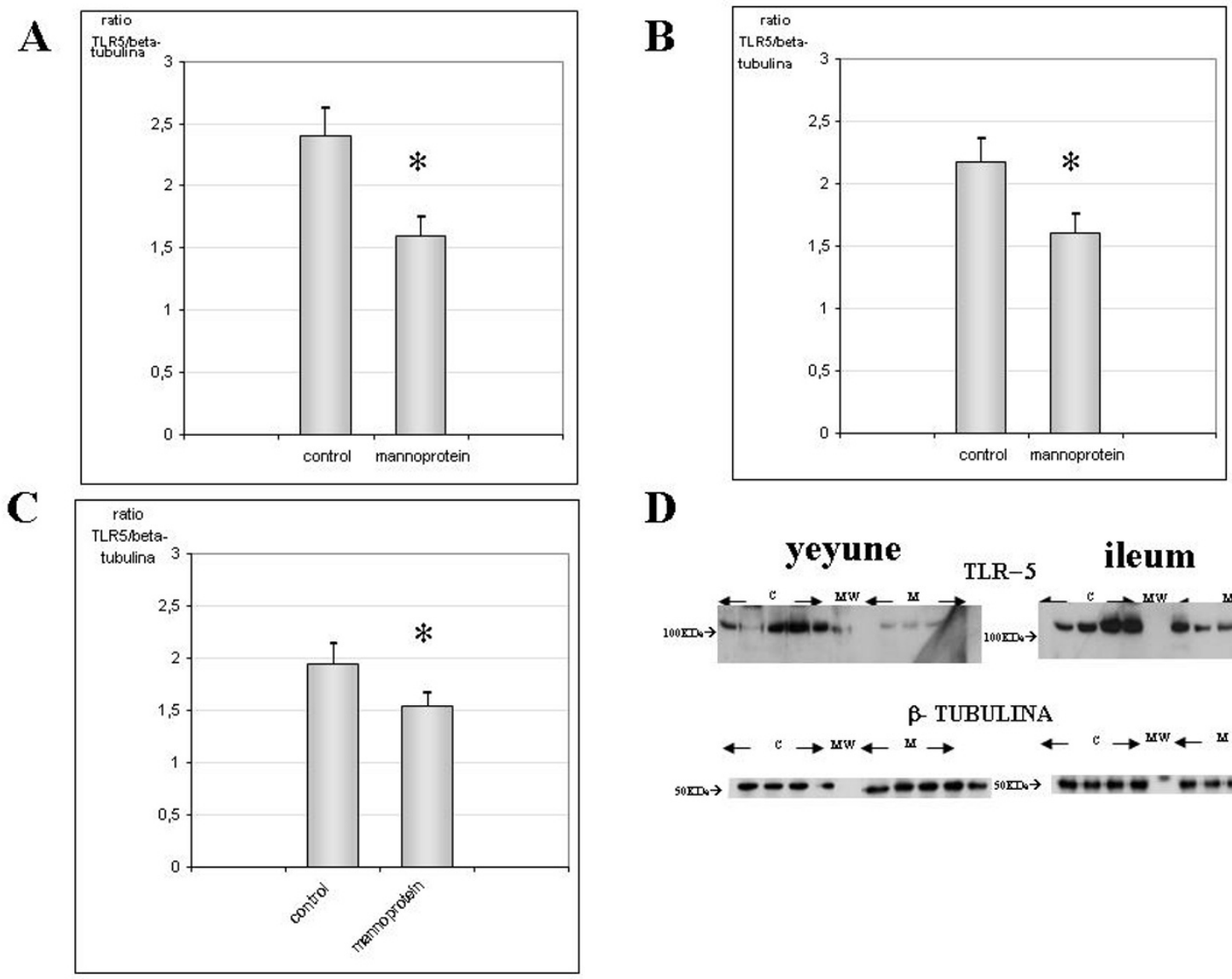

D
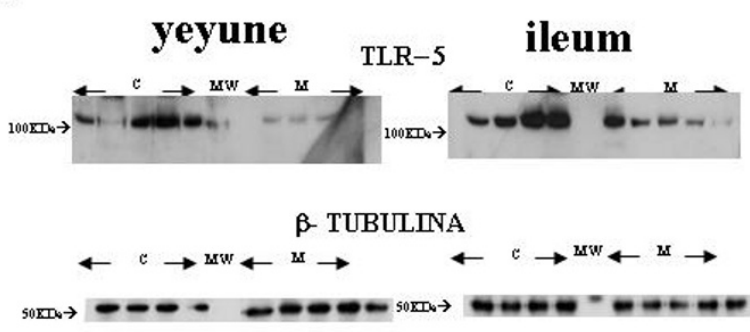

Figure 4 Quantification of TLR5 protein levels in yeyune, lleum and colon samples., Figure 4A, 4B and 4C show the levels of TLR5 protein expression in both groups for yeyune, ileum and colon respectively. In all figures an augmented expression of TLR5 is observed in the control group compared with mannoprotein ( $n=9$ control group, $n=8$ mannoprotein group). These differences were statistically significant. Figure 4D shows a representative Western-blot picture of TLR5 and $\beta$-tubuline in yeyune (left) and lleum (right) for both groups controls (designed as C) and mannoprotein (designed as M). Error bars represent the standard deviations. * Significant at $p<0.05$ compared with control.

seem good candidates to protect against infection through an intestinal route.

In our study, an inflammatory cytokine response was induced in the gut of the rats after oral infection with small amounts of a Salmonella typhimurium innoculus. In our experiments the control group showed higher TNF- $\alpha$ and IL- 6 mRNA expression than the mannoprotein-treated rats. This phenomenon was observed in the three tissues analyzed: jejunum, ileum and colon. IL-1 $\beta$ mRNA expression was only affected in the Ileum of control rats, which showed higher expression levels than treated animals. This response agrees with previous studies in murine small intestine, in which both IL-6 and TNF- $\alpha$ were induced after exposure to S. typhimurium [35-38]. IL-1 $\beta$ mRNA synthesis is increased in intestinal epithelial cells after Salmonella infection [36]. In contrast to the other cytokines studied, IL-1 $\beta$ enhances the innate response by activating NF- $\mathrm{KB}[39,40]$. We observed a clear action by mannoprotein on proinflammatory cytokine mRNA expression since these levels were lower in the treated animals than the controls. This suggests an anti-inflammatory effect whereby mannoprotein could be involved in some protective mechanisms against oral infection by Samonella typhimurium.

Our study also measured the expression of TLR5, the specific Salmonella typhimurium flagellin receptor, at both mRNA and protein levels. Our results demonstrated decreased levels of gene and protein expression in the mannoprotein treated group. Thus, mannoprotein itself is able to regulate TLR5 expression after infection by $\mathrm{Sal}$ monella. No data are available in the literature about this regulation, but there are recent studies on TLR5/flagellin interaction and the activation cascades involved in this process. These signaling cascades activate the NF- $\mathrm{kB}$ pathway and induce a proinflammatory response that mediates up-regulation of cytokines, chemokines and 
A

Proliferation

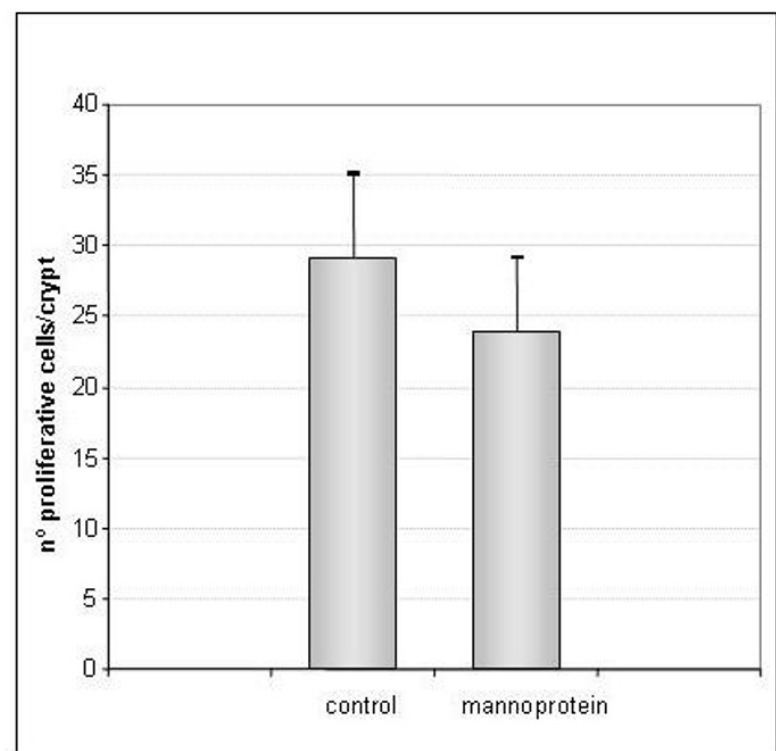

central and cripta location
B

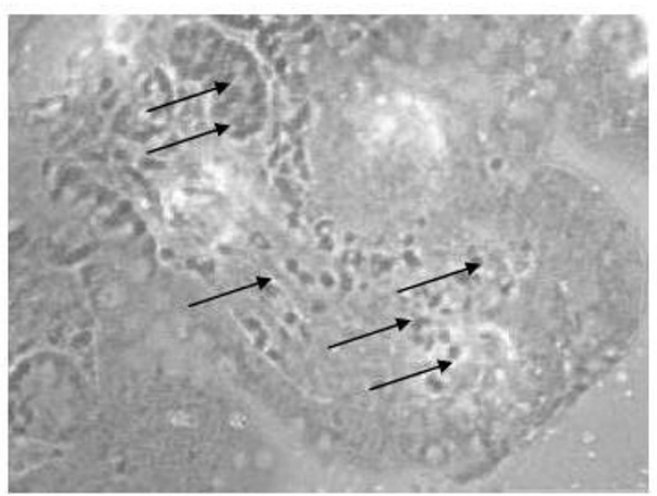

C

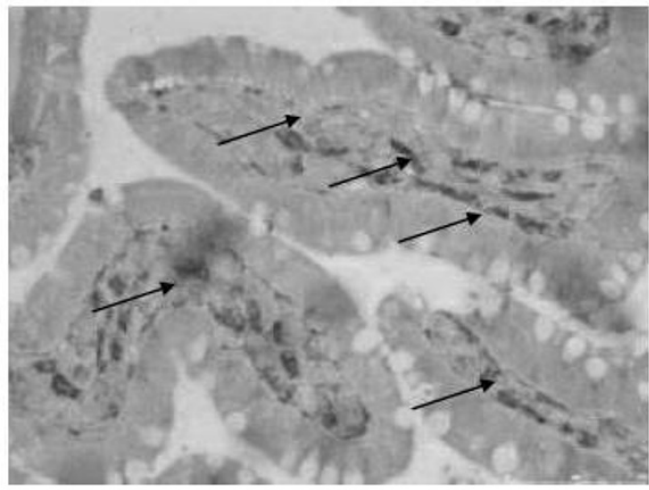

Figure 5 Number of total proliferative immunoreactive cells in ileum crypts and villi. Figure $5 \mathrm{~A}$ shows the number of total proliferative positive cells in both groups analyzed as a bar diagram. Non statistical differences were found between controls and mannoprotein group. Figure 5B shows immunohistochemical location of proliferative cells in lleum crypt in control. Figure 5C shows immunohistochemical location of proliferative cells in crypt villi in mannoprotein. Arrows indicate proliferative positive cells predominantly located in central villi and crypta. Photomicrographs at original magnification 20x. Error bars represent the standard deviations. * Significant at $p<0.05$ compared with control group.

adhesion molecules, etc. Protein modifiers of cellular apoptotic pathways are integral components of this response. This observation strongly supports the notion that apoptotic activation proceeds in parallel with proinflammatory activation [41-43]. Concerning the inflammatory response in our results, the decreased TLR 5 levels of in the mannoprotein group could explain the lower levels of IL-1 $\beta$, TNF- $\alpha$ and IL- 6 mRNA expression found in treated rats compared to their controls.

The crypt proliferative cells and apical and central apoptotic cells of the villi were immunohistochemically analysed in order to establish a possible effect of mannoprotein in proliferative and apoptotic response in Ileal tissue. Interestingly, the number of apoptotic cells in the control group was significantly higher than in the mannoprotein group. Nevertheless, when we analyzed the proliferative response in tissue these were no differences between the groups. This could be explained by the fact that the highest levels of TLR5 were found in the control group where they possibly activated both the pro-inflammatory and the apoptotic pathways as suggested in a recent study where both pathways were activated the inappropriate location of flagellin [25]. We cannot confirm this possibility, although it seems likely, because we did not determine flagellin levels or position in our study. Furthermore, other in vitro studies have indicated that Salmonella provokes apoptosis in macrophages $[44,45]$ and in HT-29 epithelial cells after 24 hours of co-culture [46]. On a different level a recent study with chickens, reports that mannoprotein diet enrichment increased jejunal villus height and thymal weight, changes that could point to an increased immune response capacity and improved gut function [47]. Summarising, the administration of mannoprotein could exert a protective effect by inhibiting the apoptosis induced by oral infection with Salmonella.

In conclusion, Mannoprotein administration in a liquid diet seems to protect the intestinal tissue against the effects of Salmonella triphymorium. This protection seems to be effected by down regulation of the proinflammatory response and of TLR5 expression, in addition to the inhibition of apoptosis. Nevertheless, the molecular 


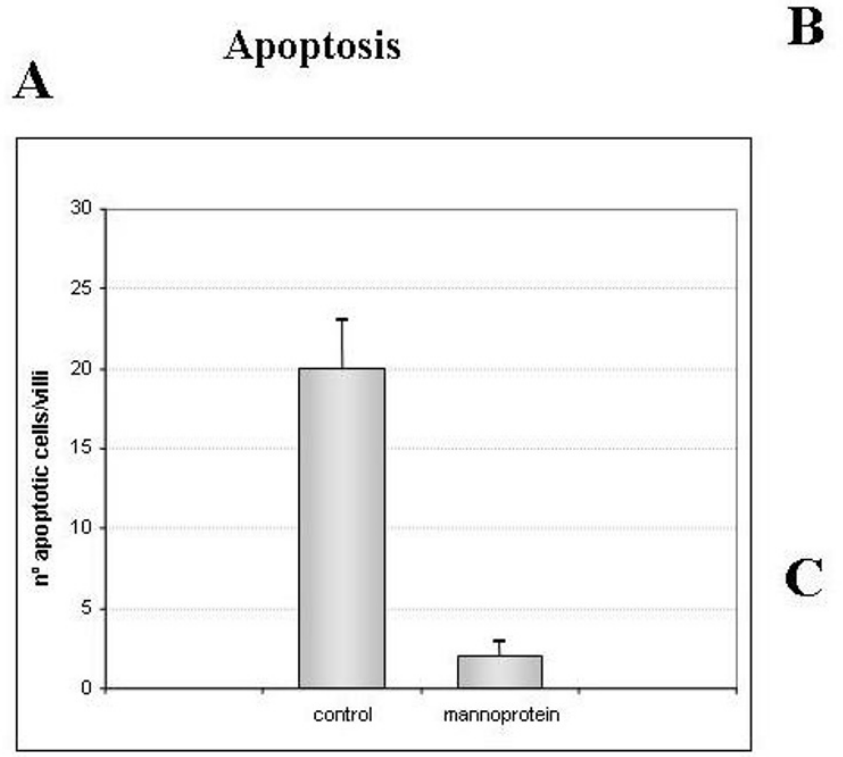

\section{Apical Location}

\section{$\mathrm{C}$}
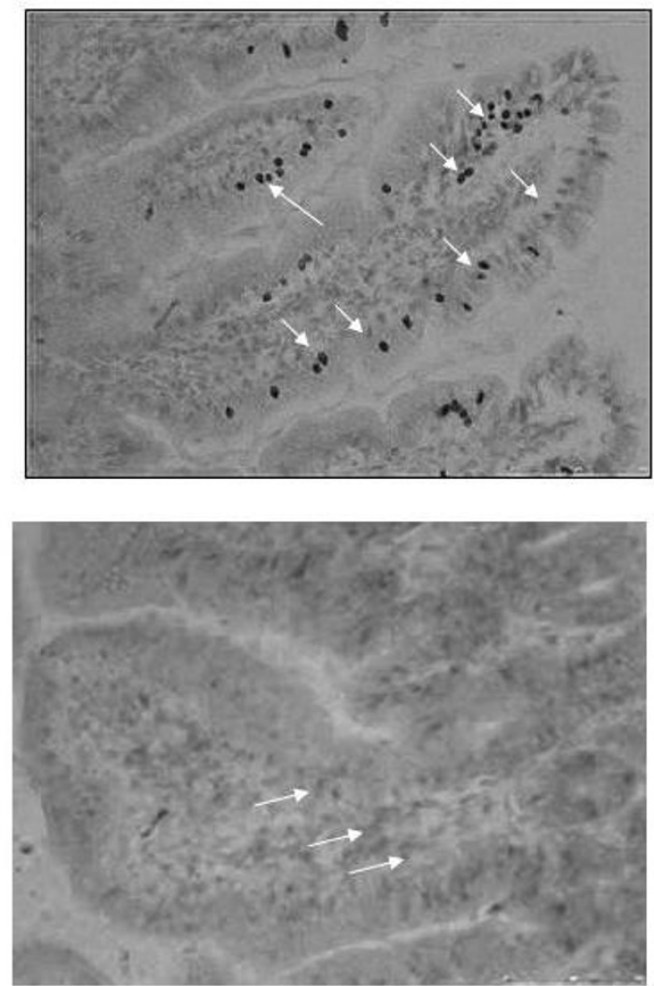

Figure 6 Number of total apoptotic immunoreactive cells in ileum villi. Figure $6 \mathrm{~A}$ shows the number of total apoptotic positive cells in both groups analyzed as a bar diagram. Significant statistical differences were found between controls and mannoprotein group. Figure 6B shows immunohistochemical location of apoptotic cells in lleum villi in control. Figure 6C shows immunohistochemical location of apoptotic cells in lleum villi in mannoprotein. Arrows indicate proliferative positive cells predominantly located in apical. Photomomicrographs in original magnification 20x. Error bars represent the standard deviations. * Significant at $p<0.05$ compared with control group.

mechanism by which mannoprotein is able to regulate this response remains unclear and is still under investigation. These results could open up new avenues in the therapeutic strategy for treatment of inflammatory gut processes induced by microbia.

\section{Conclusions}

Mannoprotein administration in a liquid diet seems to protect intestinal tissue against S. typhimurium infection. This protection seems to expressed as a lower proinflammatory response and TLR5 downregulation in gut epithelium, as well as by an inhibition of apoptosis. Nevertheless, the molecular mechanism by which mannoprotein is able to regulate these responses remain unclear. These results could open up new avenues in the use of mannoproteins as prebiotics in the therapeutic strategy for treatment of inflammatory gut processes induced by microbia.

\section{Competing interests}

The authors declare that they have no competing interests.

\section{Authors' contributions}

The work presented here was carried out in collaboration between all authors. SJP and EM defined the research theme. SJP, CL and EM designed methods and experiments, carried out the laboratory experiments, analyzed the data, interpreted the results and SJP and EM wrote the paper. VC, IQ, ME, EC, CL and IC COdesigned the experimental model, quantitative PCR, Western-blot and Immunohistochemistry experiments, and co-worked on associated data collection and their interpretation. All authors have contributed to, seen and approved the manuscript.

\section{Acknowledgements}

Sinforiano J. Posadas is a post-doctoral fellow supported by "Juan de La Cierva" program, Ministry of Science, Spain. We thank Dr. J. Mingorance for his helpfull discussion of the manuscript. This work is supported by MEC AGL2004-06933C02-02 Grant, Ministry of Science, Spain.

\section{Author Details}

'Experimental Surgery Department, La Paz Hospital, Paseo de la Castellana 261, 28046, Madrid, Spain and 2Microbiology Department, La Paz Hospital, Paseo de la Castellana 261, 28046, Madrid, Spain

Received: 16 June 2009 Accepted: 8 June 2010

Published: 8 June 2010

\section{References}

1. Tauxe R, Pavia A: Salmonellosis: nontyphoidal. In Bacterial infections in humans: epidemiology and control New York: Plenum; 1998:613-630. 
2. Wick MJ: Living in the danger zone: innate immunity to Salmonella. Curr Opin Microbiol 2004, 7:51-57.

3. Strober W: Interactions between epithelial cells and immune cells in the intestine. Ann N Y Acad Sci 1998, 859:37-45.

4. Hecht G: Innate mechanisms of epithelial host defense: spotlight on intestine. Am J Physiol 1999, 277:C351-C358.

5. Fierer J, Eckmann L, Kagnoff M: IL-8 secreted by epithelial cells invaded by bacteria. Infect Agents Dis 1993, 2:255-258.

6. Eckmann L, Jung HC, Schurer-Maly C, Panja A, Morzycka-Wroblewska E, Kagnoff MF: Differential cytokine expression by human intestinal epithelial cell lines:regulated expression of interleukin 8. Gastroenterology 1993, 105:1689-1697.

7. Eckmann L, Kagnoff MF, Fierer J: Epithelial cells secrete the chemokine interleukin-8 in response to bacterial entry. Infect Immun 1993, 61:4569-4574.

8. Witthoft T, Eckmann L, Kim JM, Kagnoff MF: Enteroinvasive bacteria directly activate expression of iNOS and NO production in human colon epithelial cells. Am J Physiol 1998, 275:G564-G571.

9. Huang GT, Eckmann L, Savidge C, Kagnoff MF: Infection of human intestinal epithelial cells with invasive bacteria upregulates apical intercellular adhesion molecule-1 (ICAM)-1) expression and neutrophil adhesion. J Clin Invest 1996, 98:572-583.

10. Elewaut D, DiDonato JA, Kim JM, Truong F, Eckmann L, Kagnoff MF: NFkappa $B$ is a central regulator of the intestinal epithelial cell innate immune response induced by infection with enteroinvasive bacteria. $J$ Immunol 1999, 163:1457-1466.

11. Philpott DJ, Yamaoka S, Israel A, Sansonetti PJ: Invasive Shigella flexneri activates NF-kappa B through a lipopolysaccharide-dependent innate intracellular response and leads to IL-8 expression in epithelial cells. J Immunol 2000, 165:903-914.

12. Takeda K, Kaisho T, Akira S: Toll-like receptors. Annu Rev Immunol 2003, 21:335-376.

13. Akira S, Takeda K, Kaisho T: Toll-like receptors: critical proteins linking innate and acquired immunity. Nat Immunol 2001, 2:675-680.

14. Athman R, Philpott D: Innate immunity via Toll-like receptors and Nod proteins. Curr Opin Microbiol 2004, 7:25-32.

15. Hayashi F, Smith KD, Ozinsky A, Hawn TR, Yi EC, Goodlett DR, Eng JK, Akira $\mathrm{S}$, Underhill DM, Aderem A: The innate immune response to bacterial flagellin is mediated by Toll-like receptor 5 . Nature 2001, 410:1099-1103.

16. Sierro F, Dubois B, Coste A, Kaiserlian D, Kraehenbuhl JP, Sirard JC: Flagellin stimulation of intestinal epithelial cells triggers CCL20mediated migration of dendritic cells. Proc Nat/ Acad Sci USA 2001, 98:13722-13727.

17. Eaves-Pyles T, Murthy K, Liaudet L, Virag L, Ross G, Soriano FG, Szabo C, Salzman AL: Flagellin, a novel mediator of Salmonellainduced epithelial activation and systemic inflammation: I kappa B alpha degradation, induction of nitric oxide synthase, induction of proinflammatory mediators, and cardiovascular dysfunction. J Immunol 2001, 166:1248-1260.

18. Liaudet L, Szabo C, Evgenov OV, Murthy KG, Pacher P, Virag L, Mabley JG Marton A, Soriano FG, Kirov MY, Bjertnaes $L$, Salzman AL: Flagellin from gram-negative bacteria is a potent mediator of acute pulmonary inflammation in sepsis. Shock 2003, 19:131-137.

19. Lodes MJ, Cong Y, Elson CO, Mohamath R, Landers CJ, Targan SR, Fort M, Hershberg RM: Bacterial flagellin is a dominant antigen in Crohn disease. J Clin Invest 2004, 113:1296-1306.

20. Zeng H, Wu H, Sloane V, Jones R, Yu Y, Lin P, Gewirtz AT, Neish AS: Flagellin/TLR5 responses in epithelia reveal intertwined activation of inflammatory and apoptotic pathways. Am J Physiol Gastrointest Liver Physiol 2006, 290(1):G96-G108.

21. Klis FM, Mol P, Hellingwerf $K$, Brul S: Dynamics of cell wall structure in Saccharomyces cerevisia. FEMS Microbiol Rev 2002, 26(3):239-56.

22. Oyofo BA, DeLoach JR, Corrier DE, Norman JO, Mollenhauer HH: Effect of carbohydrates on Salmonella typhimurium colonization in broiler chickens. Avian Dis 1989, 33(3):531-4.

23. Ishihara N, Chu DC, Akachi S, Juneja LR: Preventive effect of partially hydrolyzed guar gum on infection of Salmonella enteritidis in young and laying hens. Poult Sci 2000, 79:689-697.

24. Czerucka D, Piche T, Rampal P: Yeast as probiotics. Aliment Pharmacol Ther 2007, 26(6):767-78.
25. Naughton PJ, Grant G, Bardocz S, Pusztai A: Modulation of Salmonella infection by the lectins of canavaliaensiformis ( $\operatorname{Con} \mathrm{A}$ ) and galanthus nivalis(GNA) in a rat model in vivo. Journal of Applied microbiology 2000, 88:720-727.

26. Oyofo BA, Droleskey RE, Norman JO, Mollenhauer HH, Ziprin RL, Corrier $D E$, DeLoach JR: Inhibition by mannose of in vitro colonization of chicken small intestine by Salmonella typhimurium. Poult Sci 1989, 68(10):1351-6.

27. Line JE, Bailey JS, Cox NA, Stern NJ, Tompkins T: Effect of yeastsupplemented feed on Salmonella and Campylobacter populations in broilers. Poult Sci 1998, 77:405-410.

28. Spring P, Wenk C, Dawson KA, Newman KE: The effects of dietary mannanoligosaccharides on cecal parameters and the concentrations of enteric bacteria in the ceca of Salmonella-challenged broiler chicks. Poult Sci 2000, 79:205-211.

29. Núñez YP, Carrascosa AV, Gonzalez R, Polo MC, Martínez-Rodríguez A: : Isolation and characterization of a thermally extracted yeast cell wall fraction potentially useful for improving the foaming properties of sparkling wines. J Agric Food Chem 2006, 54(20):7898-903.

30. Havelaar AH, Garssen J, Takumi K, Koedam MA, Dufrenne JB, van Leusden FM, de La Fonteyne L, Bousema JT, Vos JG: A rat model for dose-response relationships of Salmonella enteritidis infection. Journal of Applied microbiology 2001, 91:442-452.

31. Bovee-oudenhoven IM, Wissink ML, Wouters JT, Van der Meer R: Dietary Calcium Phosphate stimulates intestinal Lactobacilli and decreases the severity of a Salmonella infection in rats. Ingeborg $M$ The journal of nutrition 1999, 129(3):607-612.

32. Gómez-Garcés JL, Castilla C: Comparative activities of ciprofloxacin, amoxicillin, and cotrimoxazole in an experimental model of enteritis caused by Salmonella non typhi. Enferm Infecc Microbio/ Clin 1992, 10(7):389-92.

33. Kierand MT, Probert HM, Smejkal CW, Gibson GR: Using probiotics and prebiotics to improve the gut health. DDT 2003, 15:692-699.

34. Ganan M, Carrascosa AV, de Pascual-Teresa S, Martinez-Rodriguez AJ: Inhibition by yeast-derived mannoproteins of adherence to and invasion of Caco-2 cells by Campylobacter jejuni. J Food Prot 2009, 72(1):55-9.

35. Arnold JW, Niesel DW, Annable CR, Hess CB, Asuncion M, Cho YJ, Peterson JW, Klimpel GR: Tumor necrosis factor-* mediates the early pathology in Salmonella infection of the gastrointestinal tract. Microb Pathog 1993, 14:217-227.

36. Klimpel GR, Asuncion M, Haithcoat J, Niesel DW: Cholera toxin and Salmonella typhimurium induce different cytokine profiles in the gastrointestinal tract. Infect Immun 1995, 6:1134-1137.

37. Rodenburg W, Bovee-Oudenhoven IM, Kramer E, van der Meer R, Keijer Gene expression response of the rat small intestine following oral Salmonella infection. J Physiol Genomics 2007, 30(2):123-33.

38. Rodenburg W, Keijer J, Kramer E, Roosing S, Vink C, Katan MB, van der Meer R, Bovee-Oudenhoven IM: Salmonella induces prominent gene expression in the rat colon. BMC Microbiol 2007, 7:84.

39. Means TK, Hayashi F, Smith KD, Aderem A, Luster AD: The Toll-like receptor 5 stimulus bacterial flagellin induces maturation and chemokine production in human dendritic cells. J Immunol 2003, 17:5165-5175

40. Santos RL, Zangh S, Tsolis RM, Baumer AJ, Adams LG, Santos RL: The attenuated sop mutant of Salmonella enterica serovar Typhimorium has the same distribution and host chemokine response as the wilde type in bovine peyer's patches. Vet Microbio/ 2003, 97:269-277.

41. Reis BP, Zanh S, Tsolis RM, Baumler AJ, Adams LG: Morphologic and molecular characterization of Salmonella Typhimorium infection in neonatal calves. Vet Pathol 2002, 39:200-215.

42. Burstein E, Duckett CS: Dying for NF-kappaB? Control of cell death by transcriptional regulation of the apoptotic machinery. Curr Opin Cell Biol 2003, 15:732-737.

43. Karin M, Lin A: NF-kappaB at the crossroads of life and death. Nat Immun 2002, 3:221-227.

44. Kim JM, Eckmann L, Savidge TC, Lowe DC, Witthoft T, Kagnoff MF: Apoptosis of human intestinal epithelial cells after bacterial invasion. J Clin Invest 1998, 102:1815-1823.

45. Knodler LA, Finlay BB: Salmonella and apoptosis: to live or let die? Microbes Infect 2001, 3:1321-1326. 
46. Paesold G, Guiney DG, Eckmann L, Kagnoff MF: Genes in the Salmonella pathogenicity island 2 and the Salmonella virulence plasmid are essential for Salmonella-induced apoptosis in intestinal epithelial cells. Cell Microbiol 2002, 4:771-781.

47. Morales-López R, Auclair E, García F, Esteve-Garcia E, Brufau J: Use of yeast cell walls; beta-1, 3/1, 6-glucans; and mannoproteins in broiler chicken diets. Poult Sci 2009, 88(3):601-7.

Pre-publication history

The pre-publication history for this paper can be accessed here: http://www.biomedcentral.com/1471-230X/10/58/prepub

doi: $10.1186 / 1471-230 X-10-58$

Cite this article as: Posadas et al., Effects of mannoprotein E1 in liquid diet on inflammatory response and TLR5 expression in the gut of rats infected by Salmonella typhimurium BMC Gastroenterology 2010, 10:58

Submit your next manuscript to BioMed Central and take full advantage of:

- Convenient online submission

- Thorough peer review

- No space constraints or color figure charges

- Immediate publication on acceptance

- Inclusion in PubMed, CAS, Scopus and Google Scholar

- Research which is freely available for redistribution

Submit your manuscript at www.biomedcentral.com/submit
C) Biomed Central 